\title{
MAPEAMENTO DO RISCO REAL DE INUNDAÇÕES NA REGIÃO HIDROGRÁFICA APACO,ALTO CURSO DO RIO PACIÊNCIA - ILHA DO MARANHÃO
}

\author{
Cristiane Mouzinho Costa ${ }^{(a)}$, Quésia Duarte da Silva ${ }^{(b)}$, Danyella Valle Barros França ${ }^{(c)}$, Alderino \\ da Conceição Garrito ${ }^{(\mathrm{d})}$
}

(a) Mestranda em Geografia, Dinâmica da Natureza e do Espaço/Universidade Estadual do Maranhão, cristianemouzinho@hotmail.com

(b) Professora do Departamento de História e Geografia/Universidade Estadual do Maranhão, quesiaduartesilva@ hotmail.com

(c) Graduada em Geografia/Universidade Estadual do Maranhão, danyellabarros-geo@ @otmail.com

(d) Graduado em Geografia /Universidade Estadual do Maranhão, alder_escoteiro@ hotmail.com

\section{Eixo: GEOGRAFIA FÍSICA E DESASTRES NATURAIS}

\begin{abstract}
Resumo
De todos os desastres naturais no mundo as inundações são os mais recorrentes e o que geram mais perdas. Neste sentido, propor medidas mitigadoras, e monitoramento destas áreas, são necessários, para isto necessita-se de um mapeamento das áreas de ocorrência destes fenômenos, desta forma,o artigo pretendeu mapear as áreas de risco real de inundações na região hidrográfica Apaco no alto Paciência -Ilha do Maranhão, e identificar quais fatores são responsáveis por este fenômeno. Para isto adotou-se os procedimentos de pesquisa bibliográfica e cartográfica acerca de inundações, perigo,risco, contexto geoambiental da área de estudo, análise deimagem de satélite, e trabalhos de campo realizados em 2015, onde mapeou-se a área de risco real de inundações, através do software ArcGIS 10.2.
\end{abstract}

Palavras chave: Mapeamento; Risco; Inundações; Ilha do Maranhão.

\section{Introdução}

Os recursos hídricos têm sido alvo das intervenções antrópicas há longo tempo, desde o surgimento das primeiras comunidades humanas, que se utilizavam deles para sua dessedentação, preparo de alimentos, higiene, construção, navegação, irrigação, etc. (BOTELHO, 2011). Neste sentido, os seres humanos conviveram com os fenômenos de cheias e inundações desde o início das civilizações, ora sendo benéficas, ora causando desastres, entretanto os desastres relacionados a cheias e inundações sempre estavam associados a eventos climáticos extremos e à ocupação humana às margens desses cursos d'água. Este processo continuou ocorrendo ao longo dos tempos e perdura até os tempos atuais, com vários agravantes do processo antrópico, como a impermeabilização do solo e consequente diminuição da infiltração e aumento do escoamento superficial. 
Apesar de o termo enchente ser tido como o mesmo que inundação estes são diferentes. De acordo com Castro et al. (2005) inundação é o transbordamento de água da calha normal de rios, mares, lagos e açudes, ou acumulação de água por drenagem deficiente, em áreas não habitualmente submersas.

Kobiyama et al. (2006) afirma que inundação que é tratada de forma popular como enchente, é o aumento do nível dos rios além da sua vazão normal, ocorrendo o transbordamento, apesar de o rio ficar praticamente cheio, tem -se uma enchente e não uma inundação.

Segundo Cred (2013) as inundações configuram-se dentre os mais impactantes eventos climáticos extremos. No Brasil estas também se configuram como o desastre natural mais frequente, à medida que causam milhares de vítimas todos os anos, e elevados custos à sociedade (HOFFMAN et al., 2014).

Hoffman et al. (2014) afirmam que a produção do espaço urbano, ocorrida de forma muito célebre e desordenada em grande parte das cidades brasileiras, faz com que este seja o palco onde ocorrem os maiores problemas decorrentes das inundações; este espaço urbano desordenado ocorre em decorrência do mau uso da terra, que por sua vez implica na formação de áreas de risco, que serão ocupadas principalmente pela população com poder aquisitivo menor, sendo assim, a mais vulnerável.

Para Tominaga et al. (2004) e Tominaga (2007), com base em Varnes (1984), Einstein (1988) e UN-ISDR (2004) risco é a possibilidade de se ter consequências prejudiciais ou danosas em função de perigos naturais ou induzidos pelo homem. Sendo para a UN-ISDR (2004) perigo como um evento, fenômeno ou atividade humana potencialmente danosa, o qual pode causar perda de vidas ou ferimentos a pessoa, danos à propriedades, rupturas sócio econômicos ou degradação ambiental. E perigo natural como processos ou fenômenos naturais que ocorrem na biosfera e que podem constituir-se em um evento danoso. Os perigos naturais podem ser classificados quanto à origem em: geológico, hidrometeorológico e biológico.

Para Hoffman et al. (2014) o risco real de inundação é a probabilidade de ocorrência destas em uma determinada área a partir dos eventos ocorridos anteriormente no local. O portal de notícias online Imirante.com em 2014, noticiou "Chuvas intensas causam mais transtornos em áreas de risco", dentre as áreas citadas na matéria está inserido a Vila Apaco, que encontra-se na região hidrográfica Apaco, que por sua vez localiza-se na porção sudeste do alto curso Paciência (Figura 1), na Ilha do Maranhão. A região em questão insere-se em um processo comum na maioria das cidades brasileiras, pois, com a expansão de cidades em áreas com alta densidade de drenagem, o risco ligado às inundações está posto. Sobre isto Alheiros et a.l (2003) ressalta que "os processos naturais só criam risco quando as pessoas ocupam o lugar onde os eventos naturais ocorrem", assim pode-se considerar as inundações como problemas 


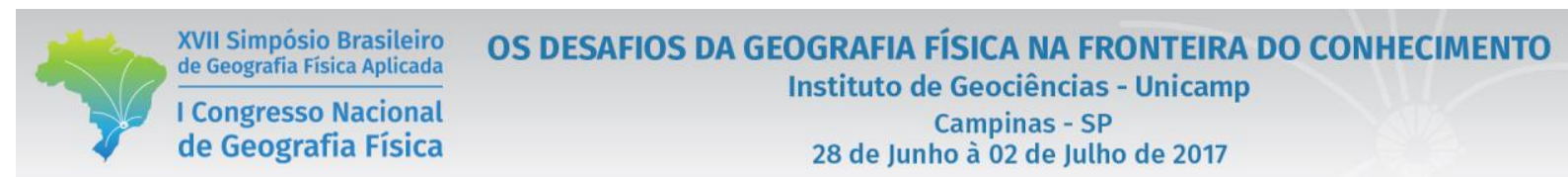

ambientais urbanos, sendo relevantes estudos que busquem interpretar geográficamente esses problemas, tendo em vista a interação estabelecida entre as dimensões sociedade e natureza, e os problemas ambientais decorrentes da pressão humana sobre os recursos naturais.

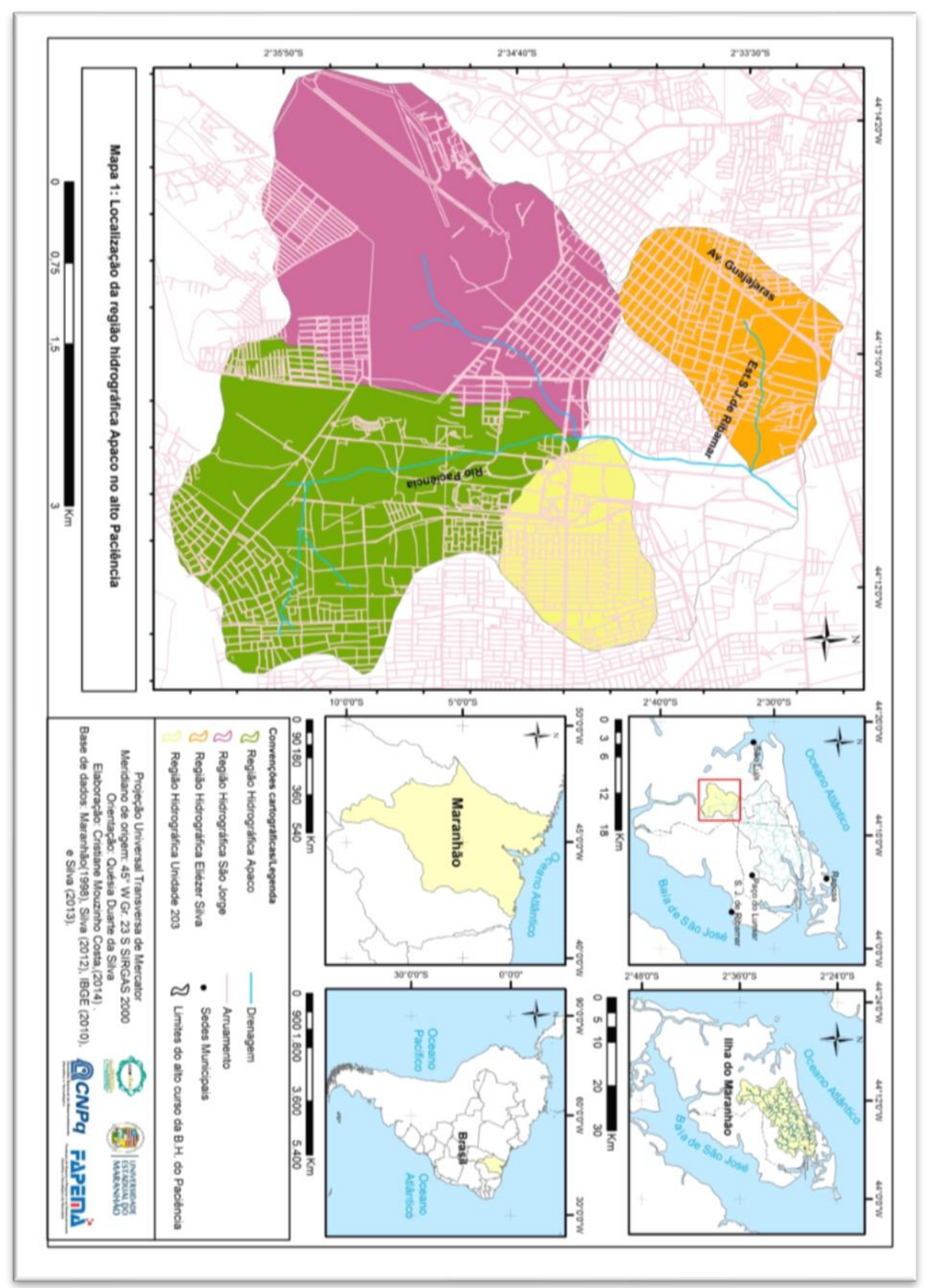

Figura 1: Localização da Região Hidrográfica Apaco (em verde) no alto Paciência 


\section{Materiais e Métodos}

a) Levantamento bibliográfico: o levantamento bibliográfico se deu a partir de pesquisas em livros, periódicos, teses, dissertações, trabalhos publicados em anais de eventos, e sites acerca de Geomorfologia Urbana, Desastres Naturais, Risco, Perigo, Enchentes, Inundações, bem como a busca de fontes para a caracterização da bacia hidrográfica do Paciência.

b) Organização do ambiente de trabalho: a organização do ambiente de trabalho se deu virtualmente no software ArcGIS for Desktop Advanced, versão 10.2, licença EFL999703439, onde foi realizado a organização por pastas dos shapefiles confeccionados nesta pesquisa, onde posteriormente foram gerados os mapas. Este software foi utilizado visto que este apresenta uma interface amigável e com estrutura em três subaplicações, capaz de executar tarefas simples ou complexas, incluindo a gestão de dados geográficos, cosntrução de mapas, análise espacial, edição avançada de dados ou ligação à base de dados externos.

c) Análise e interpretação de imagem de satélite: a imagem de satélite foi fundamental na identificação em gabinete das áreas com suspeitas de ocorrência dos fenômenos de inundação, trabalho este realizado antes das visitas a campo, tendo em vista facilitar o trabalho do pesquisador. A imagem a ser utilizada foi selecionada utilizando o software Google Earth Pro.

d) Elaboração da ficha de campo: a ficha de campo teve como objetivo nortear o pesquisador em campo para os aspectos importantes que devem ser observados in loco. Como a ocorrência dos fenômenos, características geoambientais e sociais do entorno da área de ocorrência, número de pessoas atingidas, prejuízos materiais e perdas de vidas humanas.

e) Realização dos trabalhos de campo: a realização de trabalhos de campo foram imprecindíveis para a identificação das áreas com ocorrência dos fenômenos em questão in loco, sendo estas já identificadas anteriormente na imagem de satélite, além da descoberta de novas áreas de ocorrência dos fenômenos que não foram identificados na imagem.

f) Compartimentação das regiões hidrográficas: Após a delimitação do alto curso da bacia hidrográfica do rio Paciência utilizando as curvas de nível e os divisores de água a partir das cartas DSG/ME- MINTER, datadas de 1980, utilizando o software ArcGIS for Desktop Advanced versão 10.2 licença EFL999703439, foram delimitados 4 subcompartimentos, isto é, regiões hidrográficas. Essas regiões foram inicialmente numeradas de regiões hidrográficas 1, 2, 3 e 4, entretanto, após trabalhos de campo, as regiões foram nomeadas de acordo com os nomes de ruas e/ou bairros atingidos com maior frequência pelas enchentes e inundações. 
g) Elaboração do mapa de risco real de inundações: a partir dos trabalhos de campo foi possível delimitar a área de abrangência das inundações na região hidrográfica Apaco, alto curso da bacia hidrográfica do Paciência. Esta etapa foi realizada a partir da marcação das coordenadas geográficas dos pontos de inundação nos trabalhos de campo com a ajuda do GPS, nas áreas com ocorrência dos eventos, nas duas margens dos canais. Posteriormente os pontos foram transferidos para o Arcmap, e no arccatolog, criou-se um shapefile do tipo polígono para a área de abrangência do evento. Depois, vetorizou-se a partir dos pontos de GPS, a área do polígono. Assim juntamente com os shapes de drenagem e arruamento criou-se o layout do mapa de risco real de inundações.

\section{Resultados e Discussões}

\subsection{Contexto Geoambiental da Área de Estudo}

A bacia Hidrográfica do Paciência apresenta afloramento de sedimentos do Grupo Barreiras e dos sedimentos quaternários da Formação Açuí: depósitos de mangues, depósitos aluvionares e coluvionares e depósitos de mangues e aluvionares e coluvionares (SILVA, 2012). Entretanto a região hidrográfica Apaco é composta apenas por sedimentos quaternários da Formação Barreiras, e quanto as formas de relevo a bacia possui 8 (oito) formas de relevo, sendo 5 (cinco) formas agradacionais e 3 (três) são denudacionais (SILVA, 2013). As formas agradacionais da bacia correspondem à planície de maré, terraço marinho, paleoduna, apicum e planície fluvial, e com relação às formas denudacionais são as colinas com topos planos, tabuleiros e colinas suavemente onduladas. No que diz respeito as unidades de relevo presentes na região hidrográfica Apaco do alto curso do rio Paciência estas correspondem aos tabuleiros e colinas suavemente onduladas.

No que tange aos solos segundo a caracterização de Maranhão (1998) adaptada por Silva (2013), com base nos níveis hierárquicos do Sistema Brasileiro de Classificação de Solos da Embrapa (2006), afirma-se que a região hidrográfica em questão apresenta, Argissolos e Neossolos.Utilizando a classificação climática de Koppen, que se baseia no estudo isolado dos elementos do clima, principalmente a distribuição da temperatura e pluviosidade média anual durante as estações do ano, pode-se considerar, segundo Viana (2000) citado por Mílen et al. (2006), que a área de estudo em questão encontra-se em região de padrão climático Aw, com derivação do subtipo Aw' caracterizado por ser um tipo climático quente e úmido, com um período chuvoso no primeiro semestre do ano. Segundo Sousa (2009) o clima da Ilha do Maranhão, possui uma período chuvoso (janeiro a junho) e uma período seco (julho a dezembro). 
Analisando as normais dos dados pluviométricos do município de São Luís a partir dos dados do (INMET, apud SOUSA 2009) observou a ocorrência de uma distribuição mensal das chuvas seguindo um padrão unimodal onde o máximo oscila entre os meses de março e abril, por volta de $450 \mathrm{~mm}$, e um mínimo em torno de $12 \mathrm{~mm}$ nos meses de setembro e novembro. Ainda segundo o autor supracitado, no período, precipita $85 \%$ do total da chuva anual, e a estação seca caracteriza-se por estiagens pouco severas, podendo ocorrer dias de chuva, entretanto sua insuficiência hidrológica. No que diz respeito a hidrografia quanto à hierarquia fluvial, com base em Strahler (1952) citado por Christofoletti (1980), a área de estudo apresenta 4 (quatro) canais de primeira ordem, 2 (dois) canais de segunda ordem, portanto a região hidrográfica Apaco possui uma drenagem de segunda ordem.

\subsection{Análise das áreas de inundação}

Na região hidrográfica Apaco a mancha de risco real à inundação compreende os bairros Apaco, Vila Apaco da Cidade Operária (Associação de Produtores Agrícolas da Cidade Operária) e Santa Clara (Figura 2 ). Na vila Apaco e Apaco a área de inundação abrange desde o muro da Universidade Estadual do Maranhão, Avenida das Acerolas e rua da Secretária. Segundo entrevista com um morador da Apaco, o mesmo relatou que a ocupação desse bairro ocorreu quando o governo cedeu a área para os produtores agrícolas, há cerca de 11 anos, e muitos dos que tinham a posse das terras, venderam seus terrenos. Atualmente, a área é caracterizada por ser uma franja urbana e a maior parte dos sítios que anteriormente tinham características rurais, atualmente são residências de trabalhadores da área urbana de São Luís, capital maranhense. A drenagem nesta área é oriunda da nascente do rio Paciência no bairro Santa Clara, sendo que na área da Apaco, há um córrego que foi em parte aterrado para a construção da Avenida das Acerolas. Este canal perdeu suas características naturais, pois foi aterrado em algumas partes para a construção de estradas e em outras, passa em áreas que são residenciais, como no bairro Santa Clara.

No mês de julho de 2014, o leito menor do canal apresentava no ponto visitado, aproximadamente $2,5 \mathrm{~m}$ e $20 \mathrm{~cm}$ de lâmina d'água, e atualmente passa por dentro de aproximadamente 2 propriedades particulares - De acordo com entrevista realizada com um morador desta área visitada, o muro que está sobre o rio Paciência, foi construído no ano de 2012. Em 2013, no período chuvoso e devido à força da água, o muro desabou e foi reconstruído várias vezes. Por isto, uma grade foi colocada na parte inferior do muro para facilitar o escoamento da água, evitando novos gastos. O entrevistado afirma que há 28 anos, período que reside no local, há ocorrência de enchente e inundações. Mesmo com a ocorrência destes fenômenos, percebe-se que não houve preocupação com a manutenção das características hidrológicas da área e nem com a minimização dos problemas citados. Sob a ótica das enchentes e inundações, a área mais crítica está na Vila Apaco, que surgiu por volta do ano de 2007. 


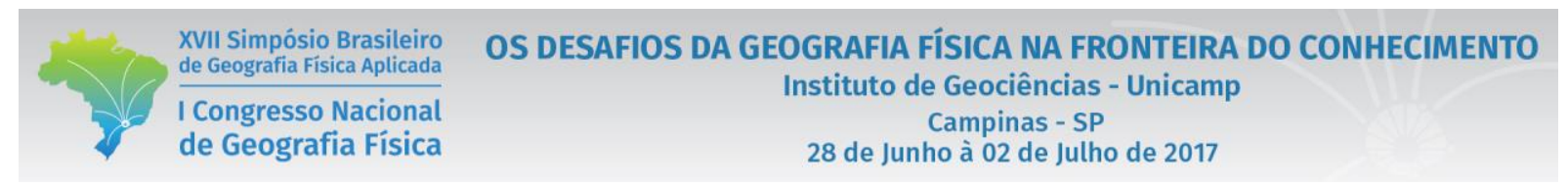

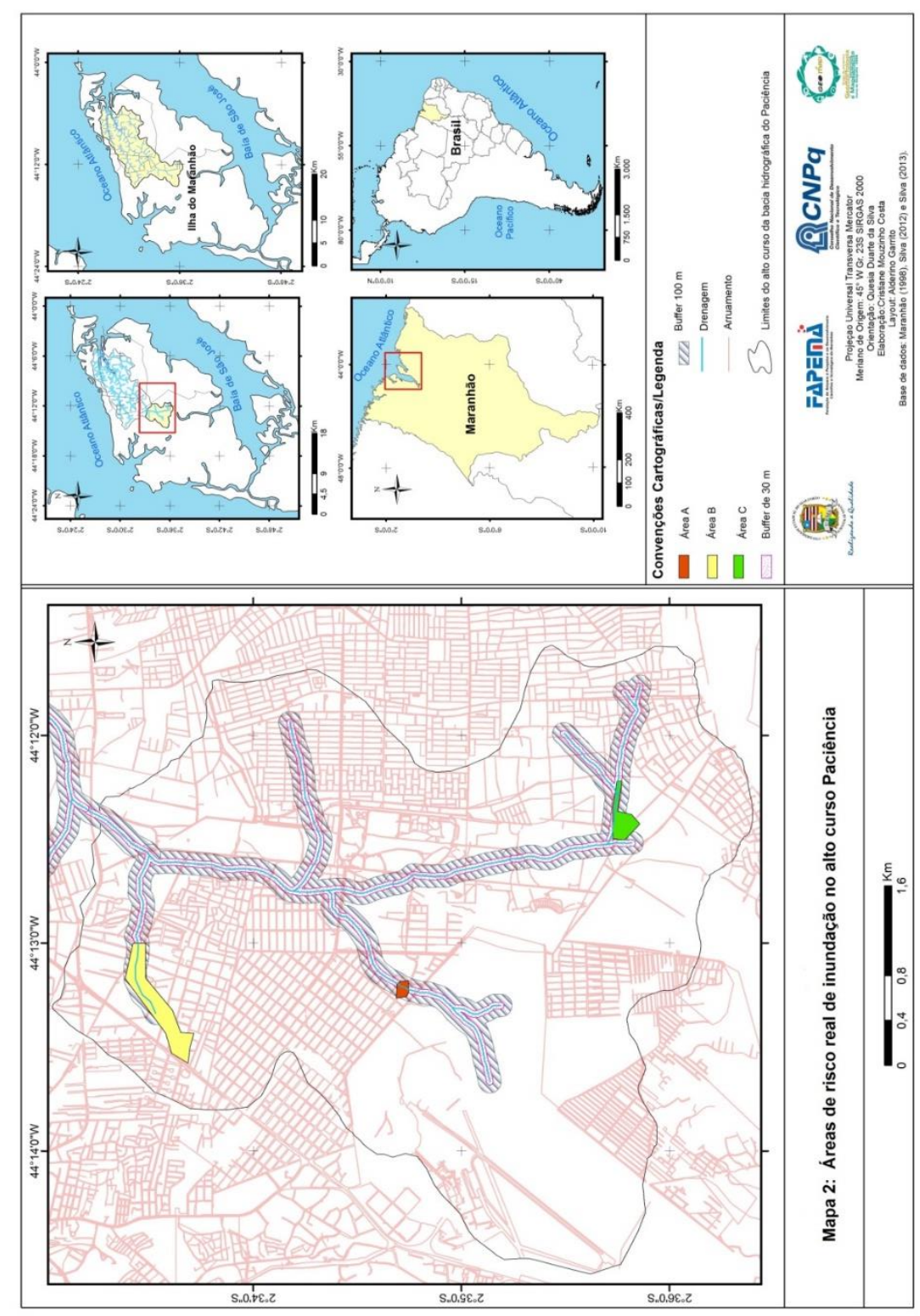

Figura 2: Mapa das áreas de risco real de inundação na região hidrográfica Apaco (Área C)

Segundo relatos, esta ocupação inadequada foi instalada no terreno do Sr. Milton Machado após o falecimento deste. Em 2013, esta vila comportava aproximadamente 165 famílias; destas, 117 encontravam-se desabrigadas devido às chuvas no mês de fevereiro do ano em questão, em virtude das inundações (G1/MARANHÃO, 2013). 


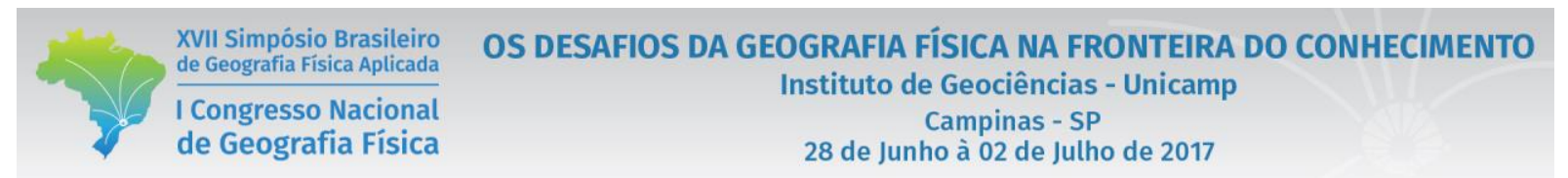

A partir de trabalho de campo realizado em 2014, pode-se afirmar que as moradias dessa área são em sua maioria de alvenaria, mas em fase de construção, sendo muito precárias as instalações. A rua ainda não possui asfaltamento e várias casas foram construídas no leito do canal e na planície de inundação, sem estrutura de saneamento (Figura 3). Toda a vila é atingida todos os anos por eventos de enchentes e inundações no período chuvoso.A mata ciliar foi totalmente retirada, restando apenas arbustos nas margens do canal. Tal fato acelera os processos erosivos, o assoreamento do canal, a velocidade do escoamento superficial, acentuando ainda mais os problemas ocorrentes.

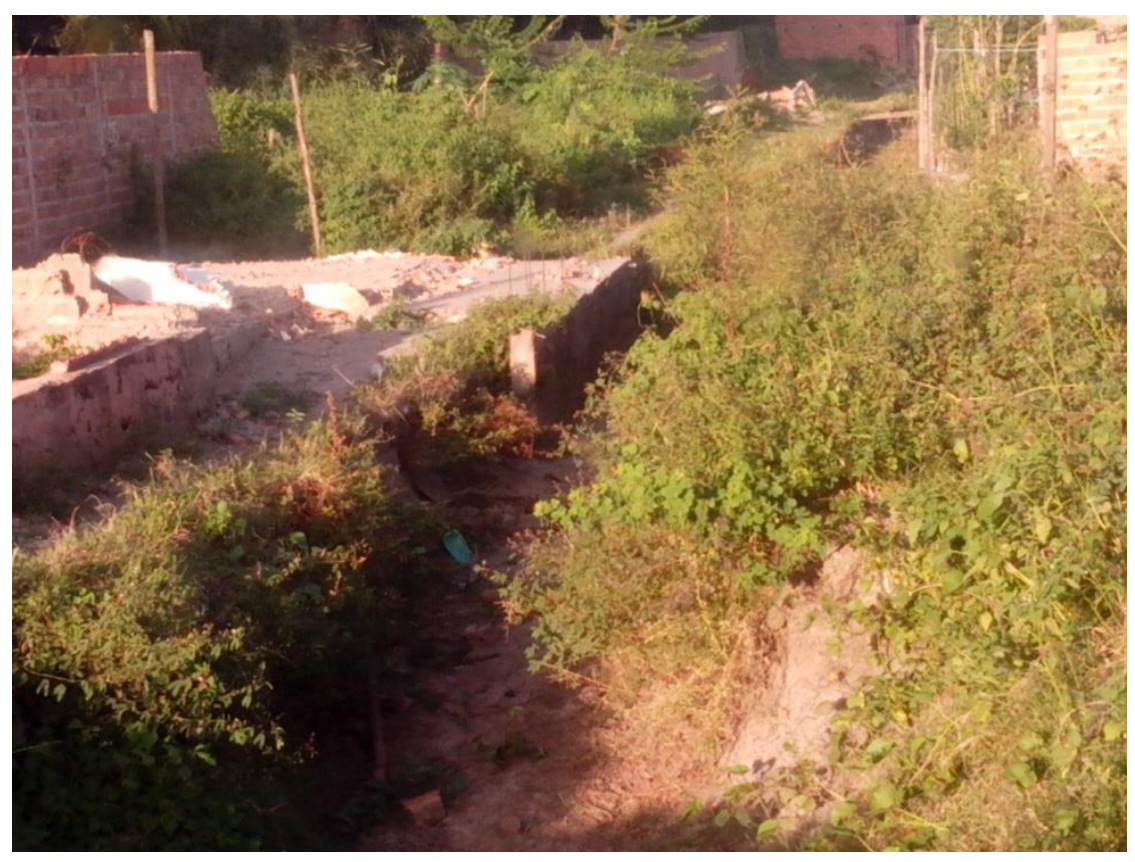

Figura 3: Moradias construídas no leito e na planície de inundação por onde passa a drenagem

No bairro Santa Clara foram identificadas com ocorrência destes eventos as ruas Lucy Sarney, Santo Antônio, João Alberto, Edmar Cutrim, João Vitor, Nossa Senhora Aparecida e rua da Paz. No bairro Santa Clara a drenagem presente nesta área corresponde a uma das principais nascentes da bacia hidrográfica do rio Paciência, sendo possível notar um poço de captação de água da Companhia de Saneamento Ambiental do Maranhão - CAEMA, entretanto este parece desativado. Neste local grande parte da nascente foi aterrada, o canal foi retificado e tubulações de esgoto foram implantadas no canal (Figura 4 ). 


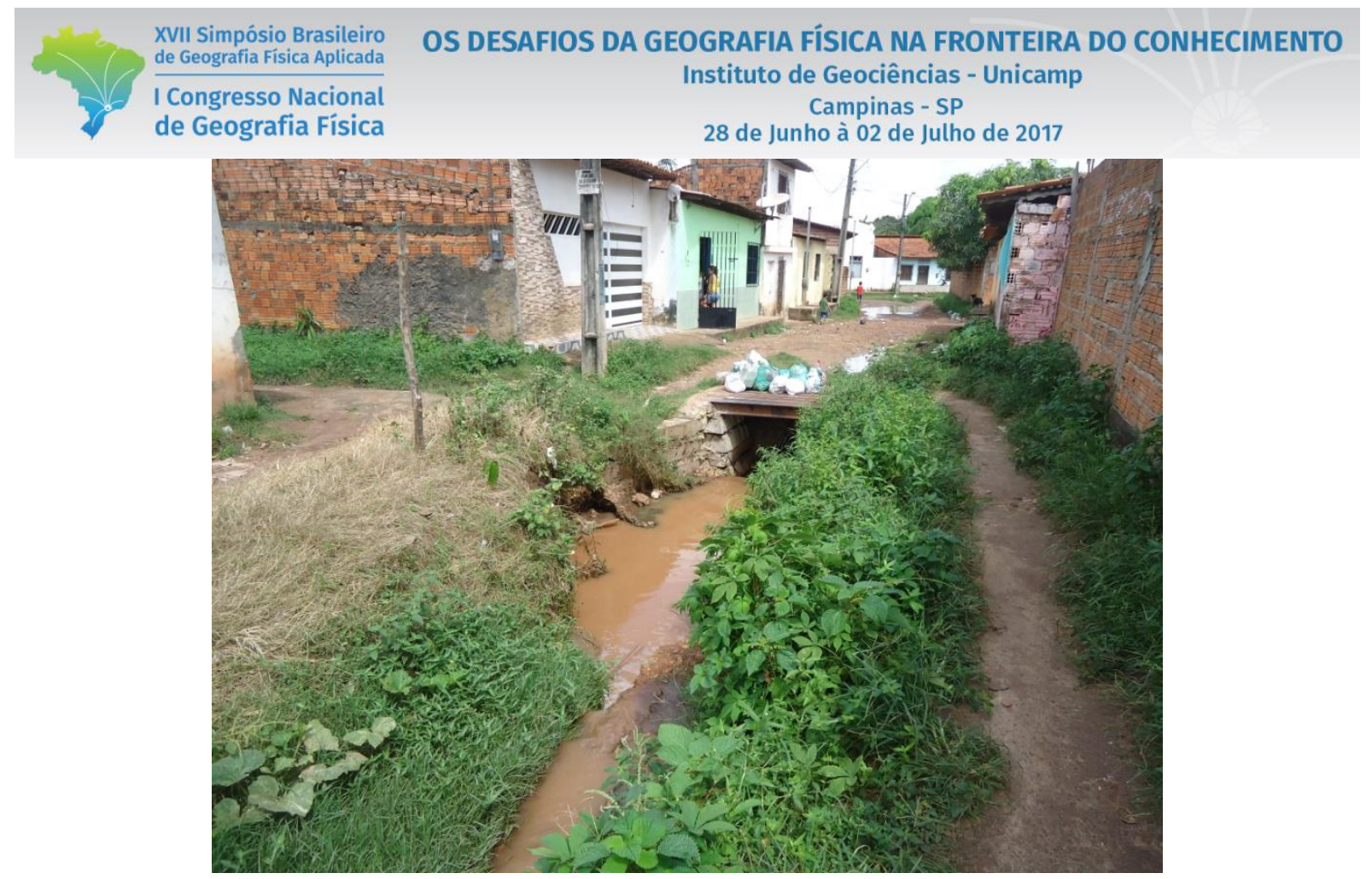

Figura 4: Retificação e aterramento da drenagem na Rua Lucy Sarney

Os efluentes são lançados neste canal além de resíduos sólidos. A maioria das casas possui calçadas altas ou batentes para se proteger da entrada da água na residência.Quando chove os moradores tem dificuldade de transitar na área por conta da inundação, ficando "ilhados". Segundo relatos a água já chegou a ultrapassar $1 \mathrm{~m}$ dentro de algumas residências, assim movéis como cama, fogão, sofá foram perdidos. A força da água também já chegou a derrubar parte de muros de residências que foram construídas onde seria o caminho natural do rio. Em entrevista com o líder da Associação de moradores do bairro Santa Clara, Laerte Teixeira, este nos informou que cerca de 12 mil famílias residem no bairro em questão, destas 400 famílias são atingidas pelos eventos de inundações.

\section{Conclusões}

A região hidrográfica Apaco é frequentemente atingida por inundações como observou-se a partir dos trabalhos de campo e em conversa com os moradores mais antigos.Constatou-se também que apesar da área de abrangência de risco real de inundação apresentar considerável impermeabilização devido à construção de moradias, a retirada da mata ciliar, ocupação da planície de inundação e do leito dos canais de drenagem, aterramento da drenagem, canalização das drenagens para instalação de tubulações de esgoto e lançamento de efluentes, assim como lançamento de resíduos sólidos diretamente nos canais de drenagem, e o acúmulo de sedimentos no fundo dos canais contribuem de forma direta para a ocorrência 


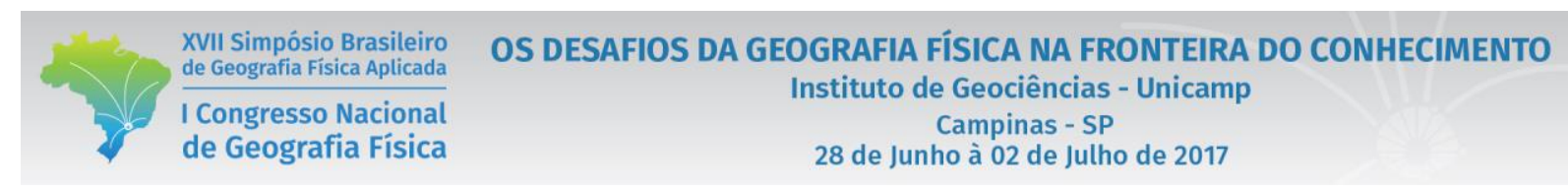

dos eventos de inundação na área, quando estes se aliam a precipitação, configuram um cenário de risco real de inundação, sendo uma área de risco alto, visto que segundo Hoffman et al. (2014) consideram áreas com registros de inundações como de risco alto, do contrário seria risco nulo ou baixo. Neste sentido, o estudo dos cenários de risco e o mapeamento das áreas de risco veem a contribuir tanto para a caracterização das populações vulneráveis, para o apoio nas ações de resposta e na consequente redução dos prejuízos socioeconômicos e humanos causados pelos desastres, visto que desta forma o poder público pode utilizar-se das informações geradas para o gerenciamento de riscos de desastres.

\section{Bibliografia}

APÓS inundação, Vila Apaco pede socorro. Portal Conectar. 2013.

BOTELHO, R. G. M. Bacias Hidrográficas Urbanas. In: Geomorfologia Urbana. Rio de Janeiro. Bertrand Brasil, 2011. cap. 3. p.72-115.

CASTRO, C. M. et al. Riscos Ambientais e Geografia: Conceituações, Abordagens e Escalas Environmental Risks and Geography: Conceptualizations, Approaches and Scales. Anuário do Instituto de Geociências - UFRJ ISSN 0101-9759 Vol. 28-2 / 2005 p. 11-30.

CHRISTOFOLETTI, A. Geomorfologia. São Paulo: Hucitec., 1980.

EMPRESA BRASILEIRA DE PESQUISA AGROPECUÁRIA - EMBRAPA. Sistema brasileiro de classificação de solos. Rio de Janeiro: 2006. Embrapa, 306p.

HOFFMAN, T. C. P.; MENDONÇA, F.; GOUDARD, G. Eventos climáticos extremos: inundaçãoe gestão de risco. In: Riscos climáticos: vulnerabilidade e resiliência associados. Jundiaí: Paco Editorial.2014.

KOBIYAMA, M. et al. Prevenção de Desastres Naturais: Conceitos Básicos. Curitiba: Ed. Organic Trading, $1^{\text {a }}$ Edição, 2006 p. 109 Disponível em: <http://www.labhidro.ufsc.br/publicacoes.html>. Acesso em: nov. de 2013.

MARANHÃO. Estudo de geomorfologia litorânea. Macrozoneamento do Golfão Maranhense. Diagnóstico Ambiental da Microrregião da Aglomeração Urbana de São Luís e dos Municípios de Alcântara, Bacabeira e Rosário. São Luís: Sema/MMA/PNMA, 1998.

MÍLEN, A. F. SOUSA, I. D. S. CAMPOS, K. S. C. PEREIRA, M. R. O. DIAS, L. B. J. Abordagem sistêmica da praia do Calhau. In: VI SIMPÓSIO NACIONAL DE GEOMORFOLOGIA. Anais eletrônicos... Goiânia. 2006. 10p.

SILVA, D. B. Feições Geomórficas da Bacia Hidrográfica do Paciência - Ilha do Maranhão. Monografia (Graduação em Geografia). São Luís. 2013. 112p.

SILVA, Q. D. Mapeamento Geomorfológico da Ilha do Maranhão. 2012. 249f. Tese (Doutorado em Geografia) Universidade Estadual Paulista, Presidente Prudente, 2012.

SOUSA, S. B.; Uso da Água de Chuva: uma alternativa para enfrentar a escassez de água na Ilha do Maranhão - MA. XVIII Simpósio Brasileiro de Recursos Hídricos. Anais... Campo Grande. 2009.

TOMINAGA, L. K. Avaliação de Metodologias de Análise de Risco a Escorregamentos: Aplicação de um Ensaio em Ubatuba, SP. Departamento de Geografia da Faculdade de Filosofia, Letras e Ciências Humanas da Universidade de São Paulo, São Paulo.2007. Tese de Doutorado 220 p + Mapas

TOMINAGA, L.; FERREIRA, C.J.; VEDOVELLO, R.; TAVARES, R.; SANTORO, J.; SOUZA, C.R. de G. Cartas de perigo a escorregamentos e de risco a pessoas e bens do Litoral Norte de São Paulo: conceitos e técnicas In: PEJON, O.; ZUQUETTE, L. eds. Simpósio Brasileiro de Cartografia Geotécnica e Geoambiental, 5: 2004: São Carlos. p. 205-216. 


\section{OS DESAFIOS DA GEOGRAFIA FÍSICA NA FRONTEIRA DO CONHECIMENTO \\ Instituto de Geociências - Unicamp \\ Campinas - SP \\ 28 de Junho à 02 de Julho de 2017}

UN-ISDR - International Strategy for Disaster Reduction. 2004 Living with Risk. A global review of disaster reduction initiatives. Inter-Agency Secretariat International Strategy for Disaster Reduction (ISDR), Genebra, Suiça. 2004. 152pp. Disponível em http://www.unisdr.org. Acesso em ago. de 2014.

UN-ISDR - International Strategy for Disaster Reduction. 2009. Terminology on Disaster Risk Reduction. Disponível em http://www.unisdr.org. Acesso em ago. de 2014.

VARNES, D.J. 1984. Landslide Hazard Zonation: Review of Principles and Practice. UNESCO Press, Paris. 56 p.

\section{Agradecimentos}

Primeiramente a Deus, que me deu a vida e sabedoria.

Aos meus pais, Murilo e Dilzenir, pelo amor, incentivo, e compreensão.

À Universidade Estadual do Maranhão (UEMA), por acreditar no potencial de seus discentes.

À Fundação de Amparo à Pesquisa e Desenvolvimento Científico do Maranhão (FAPEMA), pelo apoio, incentivo e auxílio, além de ter me proporcionado o primeiro contato com a iniciação científica.

À Coordenação de Aperfeiçoamento de Pessoal de Nível Superior (CAPES), pelo auxílio, confiança e incentivo a seus bolsistas.

Ao Programa de Pós-Graduação em Geografia, Dinâmica da Natureza e do Espaço, por acreditar no potencial de seus discentes, e nos incentivar a construir novos caminhos.

Ao grupo de pesquisa Geomorfologia e Mapeamento (GEOMAP), que me acolheu com muito carinho, e me proporciona aprender a cada dia.

À minha orientadora, Quésia Duarte, pela orientação, amizade, sábios conselhos e incentivo durante toda a pesquisa.

Aos moradores residentes nas áreas de ocorrência de inundações do alto curso da bacia hidrográfica do rio Paciência, pela receptividade e credibilidade depositadas nesta pesquisa.

Ao professor e coordenador do PPGEO, José Fernando Bezerra, pela orientação com o ArcGis, dicas preciosas, e amizade.

Aos amigos, Alder, Danyella, Ester, Rafael, Marly, Gilberlene, Pedro Wallace, e à todos aqueles que contribuirão direta ou indiretamente para esta pesquisa.

Obrigada! 